\title{
English language teaching in Malaysia: The case for a dual track English curriculum [Short Communication]
}

\author{
George Iber \\ Senior English Language Fellow \\ English Language Teaching Centre \\ Ministry of Education, Malaysia \\ E-mail: george.iber@eltc.edu.my
}

\author{
Doi:10.7575/aiac.alls.v.5n.4p.68 \\ URL: http://dx.doi.org/10.7575/aiac.alls.v.5n.4p.68
}

Received: 20/04/2014

Accepted: 18/06/2014

\begin{abstract}
"Malaysian society is constantly regaled with opinions about the falling standards of English. Falling where and in what way, is seldom mentioned."

Hyacinth Gaudart

University of Malaya

(The English Teacher, Vol XVI, December, 1987)
\end{abstract}

\section{Introduction}

It has been my privilege to work within the ELTC for a period of 10 months, learning about the English language problems and aspirations of the Ministry of Education. While tasked to work directly on a Remedial Instruction Module, it became apparent that the scopes of the initiatives in Malaysia are much more far reaching. In this paper I wish to convey my perspective in a way that may provide some lighthouse markers as the Malaysia Education Blueprint moves forward.

\section{The Goal}

As clearly stated in the English version of the Malaysia Education Blueprint 2013-2025, the language goal for Malaysia's education system is to "Ensure every child is proficient in Bahasa Malaysia and English language and is encouraged to learn an additional language" (E-12). To meet this goal, numerous initiatives have been put forward, Wave 1 (2013 - 2015) includes elements that strengthen the current system, while Wave 2 (2016 - 2020) proposes further structural changes. Wave $3(2021$ - 2025) may be said to still be beyond the horizon.

As a part of Wave 1, the Ministry has instituted the compulsory must pass subject paper in English beginning in 2016. It is strengthen the training of English language teachers through in-service training, improving communicative English learning through the OPS English program and recognized "sets or bands" of schools where English achievement is not meeting standards. Currently there are more than 1000 "hot-spot" schools that fall into this category. Remedial and differentiated methods and strategies are being developed for teachers as a part of their delivery options. A new English language curriculum for primary schools has been designed and a new LINUS for English program has been introduced (4-9).

Wave 2 is predicated upon the degree of success of Wave 1 initiatives. Wave 2 includes proposals for increased time of instruction in schools for English language instruction, use of sophisticated online delivery options, and the institution of the SPM English language paper from 2016 (4-14).

\section{The Problems}

1) Lack of preparation for the compulsory English language subject paper at SPM from 2016.

2) Defining success in language achievement according to the CEFR scale as "the linguistic fluency required to participate fully in professional and academic life" (4-10). This is the highest CEFR level, usually associated with academic native speaker abilities.

3) Incorrectly implemented, there exists the potential for a backlash against English as a required subject from students who did not receive adequate preparation, from students who are learning English as a third or fourth foreign language, and from system teachers and administrators who may shoulder the blame.

\section{The Discussion}

It is estimated that one third of the current students in Form 5 would not pass the Compulsory pass paper of 2016 if it was given today. Today is March 2014. Assuming that the stated subject paper is administered for the first time in 2016, it will be taken by students who are currently Form 3 students. In other words these students have had about 10 years of experience with the older English curriculum and methodology. In at least 1000 hot spot schools the level of 
English proficiency by the students remains at below the basic CEFR A1 level. While the programs mentioned in Wave 1 are being developed and/or implemented, they have not reached deeply into the school system. Using the cascade model of in-service training, it will be more than two years before the initiatives have been implemented, in addition, language learning is a "time-on-task" skill and must be given enough time to become effective. It is likely that many of the students sitting for the 2016 exam will not have had any specialized training. Currently students receive the equivalent of about 8.5 full days of training in English in the school setting per year. There has been an historical division since Independence regarding the use of English in public schools. More establish schools in urban areas, where English is more frequently used in government and business have traditionally benefited from an English curriculum.

The CEFR scales are well known throughout the world as a way to benchmark the language abilities of students of foreign languages and native speaker abilities. Ranging from basis A level to academically proficient $\mathrm{C}$ levels. There is also clear recognition that a beginning foreign language student would not place on the scale at all, since they would be below functional ability of the A1 level. We know that language learning takes time. To achieve a basic interpersonal functional ability in a second language can take from two to five years of full time exposure. To move from a basic fluency to academic competency requires five to ten years of usage and school training. Many native speakers never achieve academic fluency in their own language.

The learning of English in Malaysia is a complex undertaking. While Malaysia inherited English from its colonial history, that history with respect to English was mixed. Unlike many other former British colonies, English is not an official language of Malaysia, and, most importantly, it is not the medium of instruction in the schools. There are historical urban/rural divisions. In many areas of Malaysia English is seldom used. If it is used it may be the third of fourth language of the child. Consider, for example, a Tamil speaking child in eastern peninsular Malaysia who first attends a Tamil medium primary school. Basic English at the primary level may be taught using Tamil. The child moves onto secondary school where Bahas is the required medium of instruction. English is a required foreign language, but clearly the third language of the child. The total exposure of English per year in school equals about 8.5 days (136 hours of instruction / 16 hours per day $=8.5$ ). Any type of academic fluency cannot be expected with just 8.5 hours of training and usage. The CRFR level, as stated, is unrealistic for this set/band of students. It would be realistic to view this "set" of students not a remedial, but as English as foreign language learners with a separate set of benchmarks and assessments. A CEFR level of A1 or A2 may be adequate.

The history of language policy in Malaysia is visceral. Bahasa Malaya is the official language of the country and the school system. All students are required to be proficient in that language in order to receive their graduation certificate. The consequence of having two required languages in the school system has educational as well as political and economic ramifications. Malaysian students are multi-lingual, they are fluent to a degree in several languages, and English, for many students is one of those languages. English is a required subject, but not a "must-pass" subject. On the other hand, for a significant minority, English is a remote third or fourth level foreign language. English medium schools were phased out in the 1970s and efforts to use English as a medium of instruction in Math and Science were met by opposition in 2009, and it was removed. I believe that the same demographics that generated the backlash in 2009 are still in place. According to the Blueprint, by 2020 English as a foreign language may compete with other popular languages such as Chinese, Tamil, Japanese, Arabic, and even Spanish and Portuguese. Interestingly, each of these languages has had an historical presence in Malaysia at some point. English maintains its position as a world language in business and science, and for that reason will remain popular as one of the languages of educated Malaysian citizens.

\section{The Proposals}

\subsection{The two track model}

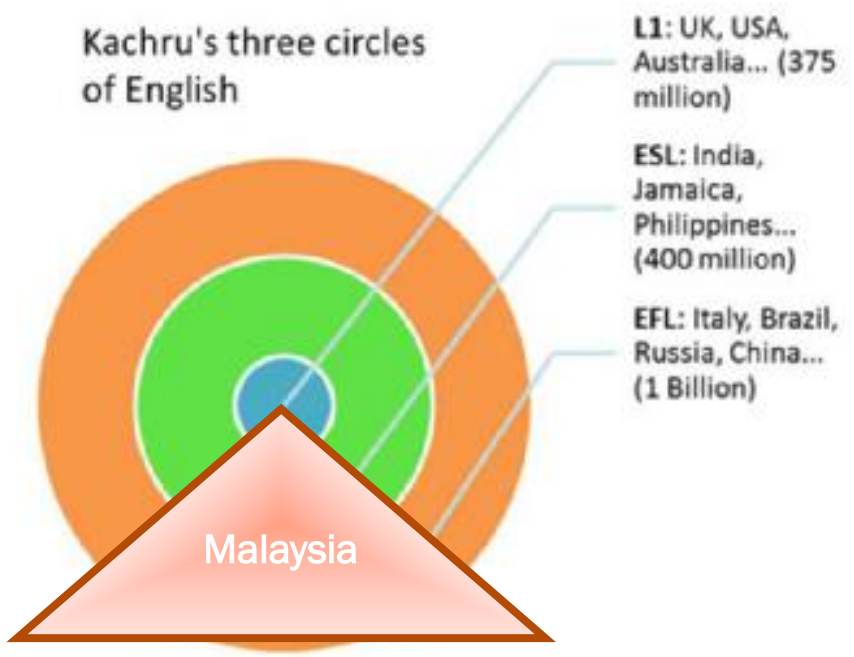


The reality of English language learners in Malaysia is that they occupy all three bands of Kachru's model. There are those who speak English as their L1 language, there is a broad second group that is exposed to a high frequency of English in the schools and the environment to classify them as ESL learners. However there is a significant third group that for reasons of location, history, socio-economic standing, poor experience in school, or recent immigrant status, should be categorized as English as foreign language learners. For these students English is third or fourth language that they are trying to dominate. These students may very well be talented multi-lingual speakers, but English remains foreign to them from an academic point of view. The total school classroom time allocated for English instruction amounts to only 136 hours. This compares to the L1 experience of approximately 5840 hours per year. An urban ESL student falls into a middle range of about 2000 hours of combined school and environmental English language use. Clearly is it not fair or reasonable to expect a student who has had so little practice with English to compete with the L1 or ESL student in the same exam setting.

Ideally a new approach should be implemented in Form 1. Students who enter Form 1 with low marks in English would be better classified as EFL students. These students should have a curriculum designed around EFL principles, with appropriate benchmarks, assessments and reasonable outcomes. This takes all onus off the student and teacher who is now classified as remedial and "low band." It provides a path to success for the student, teacher, and school system as a whole. Further it fits into the Blueprint in offering a basic English program to students. Successfully completing an appropriate assessment would allow them to continue on to vocational or tertiary schooling. These students should be offered an alternative to the standard must pass English paper.

This plan addresses the very real possibility of a backlash from the many stakeholders in the system. Offering a child a way to learn a subject rather than a certain failure or stigma of a remedial student is a progressive viewpoint. The argument that the system is not offering all students the same quality of education is not valid. Currently there are several streams within the system. It must be recognized that not all students are starting at the same level, nor is it reasonable to suppose that their progress would be evaluated properly based on an assessment that did not match what they have been taught. For some Malaysian students English must be taught and learned as a foreign language.

From a cost/benefit perspective, one can use the same English teachers that are currently in the force and many of the same materials can be adapted. A modified curriculum with appropriate benchmarks and summative assessment will be needed. Some in-service training would be necessary to educate administrators and teachers the EFL perspective. English EFL could become the model for other foreign language instruction in the country, getting a jump on the Wave 3 initiatives.

\subsection{The exam achievement distribution model}

Because the Ministry has stated that all students will take the English language subject paper in 2016, an alternative "short term" proposal is needed to avoid the appearance of a system wide failure. The educational system is in fact doing many things well and implementing many good programs, but time is a factor. Ideally the must pass would be implement only after all the other training and upgrading elements are in place, later in Wave 2. As mentioned earlier, while the initiatives are being developed and implemented they have not yet impacted the students in a significant way, and for some students the English language learning context is extraordinarily different from the design of the current curriculum.

The risk is that if a large percentage of students do not pass this exam they will not receive their secondary certificate, schools and teachers will be viewed as failing the students. The result could even be felt in national politics, the consequence being a further pullback of the special status that English language training already holds.

At minimum, a review of how the SPM English results will be evaluated is necessary. Assuming a bell curved approach, students whose individual scores are in the average range of scores would be targeted for the standard SPM pass paper. Students in an upper range of the standard deviation could receive honors recognition. Somewhat lower range of student scores, perhaps -1.5 standard deviations from the mean, would receive a basic paper. In effect, one exam with three passing levels. In this configuration there will be some failure rate, about $10 \%$ of the students will not pass using this model. However, if those students do pass all the other secondary subjects then they too should be granted an exemption and awarded a secondary certificate. Their failure to pass may be the result of other variables, including special education needs. No student should be denied a secondary certificate if the only failure on their record is the SPM English exam. To be compassionate to the students who need the most support within the educational system, a flexible approach to the initial English exam requirement is in the best interest of all.

\section{Summary}

If properly conceived, aspects of both proposed models could be maintained into the future. In the long view two approaches to the teaching of English curriculum are inevitable, which means two assessment schemes. One view is to see lower achieving students using a deficit model; the other is to recognize the smaller role English may play in their lives. Although one summative assessment could serve for both curriculums, its development would have to be carefully managed. Students and teachers need to know what is expected of them. In addition to English being a world language, Bahasa Malaya is a unique language with many loan words from English; English will always therefor be a part of the educational landscape in this country, whether it is a language of instruction, an academic second language, or a foreign language.

Specialized language methods, strategies, and approaches have an important role to play in the classroom, as do adequate teacher skills, but language is fundamentally a question of time and practice. The Blueprint acknowledges as 
much when it suggests that Wave 2 include, "increasing the exposure time to the English language from the current 15$20 \%$ "...(4-14). While more classroom time is clearly valuable, if the student's interaction with English is confined only to the school and classroom, he will be unable to move beyond the basics.

Given the realities of language learning, it is important that we view this "remedial" group of language learners as beginners. These form 1 students should be provided a basic curriculum structured around the principles of foreign language teaching and learning. This group of students should not be expected to achieve the same outcomes as those who have a different level of exposure to English in their daily lives. A unique, exciting, and meaningful curriculum can be designed and implemented for this group of students with its own benchmarks and assessment outcomes. 